This item was submitted to Loughborough's Research Repository by the author.

Items in Figshare are protected by copyright, with all rights reserved, unless otherwise indicated.

\title{
Technology adoption factors in the digitization of popular culture: Analyzing the online gambling market
}

PLEASE CITE THE PUBLISHED VERSION

https://doi.org/10.1016/j.techfore.2019.119717

PUBLISHER

Elsevier

VERSION

AM (Accepted Manuscript)

\section{PUBLISHER STATEMENT}

This paper was accepted for publication in the journal Technological Forecasting and Social Change and the definitive published version is available at https://doi.org/10.1016/j.techfore.2019.119717.

\section{LICENCE}

CC BY-NC-ND 4.0

\section{REPOSITORY RECORD}

Scott, Stephanie, Paul Hughes, lan Hodgkinson, and Sascha Kraus. 2019. "Technology Adoption Factors in the Digitization of Popular Culture: Analyzing the Online Gambling Market”. Loughborough University. https://hdl.handle.net/2134/9537131.v1. 


\section{Technology Adoption Factors in the Digitization of Popular Culture: Analyzing the Online Gambling Market}

\section{Introduction}

The digitization trend has stimulated a disruptive market for inventing and commercializing a broad scope of digital consumer services (Kamolsook et al., 2019; Schmidthuber et al., 2019; Oner at al., 2013). Firms have had to adjust to the disruptive impacts of web-based communications, marketing, and service delivery (Bakos, 1997; Lamoreaux \& Sokoloff, 2003; Rigby et al., 2016). Such developments have subsequently enabled firms to pursue an arrangement of entrepreneurial opportunities (Ferreira et al., 2019; Kraus et al., 2019) across vast geographic regions. As such, this has spawned numerous digital, smart, and internet-based services at a meteoric pace (Lee \& Trimi, 2018). However, the factors driving the adoption rates of digital services are not yet fully understood (Gomez et al., 2017; Cook, 2017; Venkatraman et al., 2018). This is particularly evident in the global emergence of popular cultural activities and services in a digital format. Understanding the consequences of technological disruptions in popular cultural activities and services is of the utmost importance, yet questions remain as to the factors driving market diffusion. The intent to use these services, perceptions of how consumption experience has shifted within societies, and what factors influence the adoption of disruptive technological services requires further research.

The low-cost and ease of product development, alongside the easily accessible nature of these services for consumers, have reduced the traditional barriers lone entrepreneurs previously met when entering markets. The product type and incremental nature of development has fostered creative development (Rajapathirana, 2018), however organizations 
still need to understand the micro-level elements of their environment to innovate appropriately (Ali et al., 2018). A holistic understanding involves a comprehensive view of the internal and external factors influencing technology development and diffusion (Ferraris et al., 2017). However, the determinants of digital service diffusion across contexts and the wide range of variables that are embedded within the social environment and their consumer perceptions requires further empirical examinations (Höflinger et al., 2018; Li et al., 2018).

This study focuses on the psychological and social aspects of popular cultural activities, in particular the online gambling industry. Popular (pop) culture is typically recognized as set of entertainment activities that are broadly accepted within a society. These activities typically have widespread acceptance, and are mass distributed within a society. While gambling is broadly available across many global markets, the acceptance of this activity varies between societies due to perceived risk. Much of the research within the gambling setting has focused on the need to observe various behavioral factors with the hope of mitigating the impact of social loss within the traditional brick and mortar realm. Nevertheless, some studies conducted into online gambling has retained a narrow focus primarily on gambling addictions (Israeli et al., 2018; Kairouz et al., 2012; Lee \& Pearce, 2007; Park et al., 2011; Fogel, 2011). The emphasis has been on the impact of the readily available access to online gambling that vulnerable consumers have (or will have) under market liberalization but has not yet examined the cognitive factors that drive an individual to use these services in the first place. The research has not fully explored how the transition to a digital service disrupts the consumption experience. A digital consumption experience provides users the opportunity to engage discretely in behaviors that are controlled and monitored by social environments when delivered in the brick and mortar format, which is essential to understanding the rate of adoption and marketing approaches (Gomez et al., 2017). This study proposes that through examining the underlying factors that influence 
individuals to gamble online provides an alternative approach to understanding the factors influencing the adoption of disruptive digital services.

This gives rise to the research question: "What psychological factors impact the consumer's intention to use digital platforms to gamble online?" As perceptions surrounding gambling vary between regions, we address this question through a comparative study of online gamblers from the United States (US) and the United Kingdom (UK). The theories of reasoned action and planned behavior (Ajzen \& Fishbein, 1969) are integrated to this end and identify attitudes, subjective norms, and perceived behavioral control that can predict behavioral intention. To our knowledge, there has not yet been a study that examines this context using this approach. The paper is structured accordingly: first, the theoretical background to the study is presented, and the online gambling setting outlined. The development of study hypotheses follows this. Next, the research methods adopted are outlined followed by the data analysis, and presentation of results. Next, the findings are discussed and implications for service theory and practice are drawn. Final conclusions bring the paper to a close.

\section{The adoption factors of digital entertainment services}

\subsection{The digitization of popular culture industries}

The popular culture industries are generally understood as those that produce activities or artefacts that result in a mass diffusion within a society (Storey, 2018). These products and services are typically aligned with mainstream trends in the arts, music, sports, television, and/or gaming. Within cultural studies, popular culture is generally viewed in contrast to other higher forms of cultural activities, such as folklore, language, and political 
ideologies (Hall, 1980; Jones, 2005). This is largely due to criticism of its mass commercial appeal and the subsequent influence these topics might have traditional and prevalent social norms. Yet, understanding how these products shape social perceptions and the processes which promote widespread acceptance is of utmost importance for addressing the needs of contemporary cultural and social agenda. This is especially evident given the global digitization trends and the new opportunities for these products to transcend geographical boundaries.

\subsubsection{The popular culture context: the online gambling industry}

Gambling includes any game of chance that involves a monetary wager; such settings comprise sports betting, casino games, lotteries, bingos, and so forth. The online aspect can be facilitated by any device (computer, tablet, or smartphone) that has an internet connection and allows a consumer to make a monetary wager remotely (e.g., outside of a casino or betting shop). There is a rich and well-developed body of literature regarding traditional gambling, ranging from understanding social implications, addictions, and different psychological aspects; but with general agreement that individual's perception of the possibility of winning involves cognitive abilities (Ahn \& Back, 2018).

However, few studies address the online gambling context. Notable exceptions include Kairouz et al. (2011) who characterize socio-demographic profiles of Canadians who gamble online and those who do not, to examine if an online gambler exhibits more symptoms of addiction and are, thus, more vulnerable; while Lee and Pearce (2007) conducted a similar socio-demographic study of Australian internet gamblers versus traditional Australian casino gamblers. Both studies conclude that specific socio-demographic traits do not adequately determine the motives of online gamblers. 
In contrast, many studies have adopted a design-perspective focusing on the features of gambling websites and consumer perceptions that surround them. Siemens and Kopp (2011), for instance, analyze online gambling versus traditional casino gambling in the US and found that the online environment influence time spent, but not necessarily money spent. Nelson et al., (2008) examine responsible gambling features in the UK and the purchasing behaviors of those consumers that impose self-limits. They report that those consumers who utilize this feature are likely to spend less money and devote less time to playing. Another notable example is the study by Cotte and Latour (2009), who contrast Las Vegas casino gamblers with online gamblers to identify if differences in experience attract consumers to these different formats. They observe how the attractive features of gambling online from the perception of the consumer was the sense of anonymity that the consumer felt and its antisocial aspects; this is contrasted by the findings reported by Choi and Kim (2004) in the Korean context, who report that online players were more satisfied when social interaction features were available. Another Korean study conducted by Park et al. (2011) posits that extraversion and agreeableness can be linked with Korean consumer motivations to play online casino games.

Taken collectively, the variance between the findings of the North American, UK, and Korean studies supports the assumptions that variance exists between countries and cultures when examining attitudes and behaviors to online gambling. This is emphasized by Safón (2010, p. 85) who observes that while 'commercial gaming markets are governed by regulations whose raison d'être has economic (market failures), political and social foundations...the latter can be deemed to be the most important'. Indeed, Ahn and Back (2018) confirm that offline behavioral intention is influenced most be the social experience or social perception of service consumers. Though most studies lack a cross-cultural comparison, Gainsbury et al. (2013) examine online gamblers in 96 countries to examine 
perceptions toward consumer protection measures. They reported differences in satisfaction levels of responsible gambling features across the globe but did not integrate cross-cultural motives for participation as an explanatory of the varied satisfaction levels reported among the countries examined; thus cultural comparisons of online gambling perceptions and behaviors is still lacking.

\subsection{Determinants of behavioral intent: technology acceptance model}

Within the realms of digital service research, a considerable amount of work has utilized the Technology Acceptance Model (TAM) to understand the psychological process from which consumers form early perceptions of digital services (e.g., Schmidthuber, 2019; Wang \& Sun, 2016; Oner et al., 2013). Introduced by Fred Davis (1989), the TAM was developed to understand the behavioral constructs that influence the use of a new technology and is derived from information systems theory that suggest the attitudinal variables of perceived usefulness and perceived ease of use are core predictors for individual acceptance or rejection of technology-based products or services (Davis et al., 1989). As an extension of the theory of reasoned action/planned behavior, TAM has been widely applied, modified, and debated over the past 25 years (Wang \& Sun, 2016; Marangunic \& Granic, 2015). An implicit assumption found within the TAM and indeed the theory of reasoned action/planned behavior is that human beings utilize rational and systematic decision-making processes (Davis, 1989).

The theory of reasoned action has become the classic psychological theoretical perspective to examine individual-level motivations to engage in a wide range of voluntary behaviors. The premise of the TAM is that positive attitudes and perceptions of control are the core variables influencing behavioral action. Although the application of the theory of 
reasoned action is regarded as having a high level of accuracy in predicting human behavior, it was later criticized for its simplicity, and many researchers have speculated that it neglects other significant variables that influence behavioral intentions. For instance, the BentlerSpeckart extension of the theory of reasoned action includes prior behavior and eagerness as primary variables that directly affect intentions to act, but this has also been heavily criticized for over-looking social influence and thereby lacking predictive validity across varying contexts (Fredricks \& Dossett, 1983). Responding to these limitations, Ajzen (1991) extended the theory of reasoned action to include the pressures of social conformity through the addition of the subjective normative construct. In adjusting the original reasoned actionoriented model through the identification of the influence of perceived behavioral control as a fundamental variable in predicting behavioral intentions, Ajzen (1991) introduced the theory of planned behavior.

Within this version of the theory of planned behavior, the combined influence of subjective norms, attitudes, and perceived behavioral control directs the purposeful intent to engage in an activity (or behavior). While it has been widely used, modified, and extended to serve as an influential and core theoretical base in studies that seek an explanation and prediction of human behavior across a wide range of contexts (King \& He, 2006; Workman, 2007), the theory has continued to face sustained criticism due to its lack of generalizability across contexts. For instance, Venkatesh and Davis (2000) emphasize that subjective norms will play a more significant influence in behaviors that are mandatory (not voluntary), which will vary particularly between country contexts. Whilst the model exhibits the ability to be generalizable, the level of influence of each of the constructs on behavioral intent has varied (Truong, 2009). For instance, the constructs and model have adapted to include the influence of perceptions of economic wellbeing (Verma \& Sinha, 2018), age (Wang \& Sun, 2016), technology type (Kamolsook et al., 2019), and local identity (Sepasgozar et al., 2019). 
Though the model has been adapted to predict the use of several different online services (Baker \& White 2010; Al-Debei et al., 2013), we subsequently argue that the explanatory power of the model is context specific and, thus, requires further modification to capture digital service consumer engagement. Specifically, the role of wider social influencers that are fundamental to contemporary digital marketplaces such as the role of media in promoting online gambling.

The analytical model is presented in Figure 1 and represents a development of the TAM by incorporating wider social subjective norms, beyond only close subjective norms.

\section{...Insert Figure 1 Here...}

\subsubsection{Attitudes}

Much of the research conducted on online gambling to date has examined attitudinal characteristics of the online gambling consumer (Kairouz et al., 2012; Lee \& Pearce, 2007; Park et al., 2011; Fogel, 2011). Attitudes are latent, yet complex, psychological constructs which are developed in response to negative or positive perceptions (Ajzen \& Fishbein, 1969). Although general attitude measures can affect the different strength of an individual's intention to perform, it has not provided conclusive evidence of a specific group that is more prone to be a consumer of online gambling. The theory of reasoned action/ theory of planned behavior adopts a non-traditional method for collecting attitudinal perceptions. According to the model, attitude is measured by the personal evaluations of the act in question (Ajzen \& Fishbein, 1969; Fredrick \& Dossett, 1983; Fitzmaurice, 2005). The application of attitude measurement here depicts the 'individual's attitude towards performing a particular act in each situation for a given object, rather than his attitude toward the object or class of objects per se' (Ajzen \& Fishbein, 1969, p. 402). Therefore: 
H1. Attitudes will be positively related to online gambling intention in a) the UK and b) the US.

\subsubsection{Subjective norms (close)}

In addition, consumer attitude is influenced by the social impact on the individual which determines the behavioral intention to perform the act in question. This subjective norm refers to the perceived social pressures generated by those close to the individual, to perform (or not) the behavior (Ajzen, 1991). In continuing the application of the theories of reasoned action and planned behavior, subjective normative beliefs are said to influence an individual's intention to perform a given act. Subjective norms are designed to understand the participants' evaluation of the views that significant others hold toward online gambling as well as the individual's motivation to comply within personal relationships (Ajzen, 1991). Many studies have found a positive relationship with subjective norms and behavioral intent (Al-Debei et al., 2013; Heirman \& Walrave, 2012; Truong, 2009). Thus:

H2. Subjective norms will be positively related to online gambling intention in a) the UK and b) the US.

\subsubsection{Subjective Norms (Social)}

The emergence of digital markets has impacted the way that society communicates and interacts (Kaplan \& Haenlin, 2010). While social media applications have been studied in the business to consumer context (Nadeem et al., 2015; Eggers et al., 2017), such applications are typically only studied in advertising and sales contexts from a content marketing perspective. As a result, social media researchers focus on the company and content (Parent et al., 2011), but not typically on how social media impacts the psyche of the user in the early 
service interaction phase. 'Subjective norms (social)' is the label adopted to classify influencers that have an impact on behavioral intentions that may not have close ties to the individual (e.g. the media, peer evaluations, and word of mouth marketing). Consequently:

H3. Subjective norms (social) will be positively related to online gambling intentions in a) the UK and b) the US.

\subsubsection{Perceived behavioral control}

Ajzen's (1991) development of the theory of planned behavior from the theory of reasoned action defined perceived behavioral control as an additional variable that influences behavioral intention. This variable is defined by the individual's belief in their capacity to achieve successful outcomes and is likely to influence an individual's formation of behavioral intent (Heirman \& Walrave, 2012). Perceived behavioral control adds a focus on individuals' self- efficacy towards the successful outcome of the behavior (Ajzen, 1991). Therefore, perceived behavioral control is as an individual's belief in their ability to be successful in performing the behavior in question and reflects the belief that the individual can achieve desired outcomes: 'For instance, even if two individuals have equally strong intentions to [...] (act on the behavior) the person who is confident that $\mathrm{s} /$ he can master this activity is more likely to persevere than is the person that doubts his ability' (Ajzen, 1991, p. 184). Current research has not addressed the possible effects of perceived behavioral control on the act of gambling. This study expects that perceived behavioral control will have a significant effect on behavioral intention; hence:

H4. Perceived behavioral will be positively related to online gambling intentions in a) the UK and b) the US. 


\subsubsection{The behavioral intention and behavioral action relationship}

Within the application of the TRA/TPB 'intentions to perform behaviors of different kinds can be predicted with high accuracy from attitudes toward the behavior, subjective norms, and perceived behavioral control; and these intentions, together with perceptions of behavioral control, account for considerable variance in actual behavior' (Ajzen, 1991, p. 50). Within the theory of reasoned action/planned behavior; the intention determines the performance or non-performance of specific behavior (Fredricks \& Dossett, 1983). Thus, for any research to apply this theory to explaining consumer behavior, it is necessary to determine the 'intent' to purchase. According to the theory of the TAM, the intent determines an individual's actual behavior to do so (Fredrick \& Dossett, 1983; Ajzen \& Fishbein, 1969). Previous studies have demonstrated strong relationships between behavioral intention and the performance of the behavior (Al-Debei et al., 2013). This study expects that gambling intention will be positively related to actual online gambling behavior in both the US and UK. Thus:

H5. Online gambling intentions will be positively related to gambling online behavior in a) the UK and b) the US.

\section{Methodology}

\subsection{Methods}

An internet survey was developed following the prescriptions of Dillman (2000) and administered to a sample of 1,000 individuals from the US and the UK respectively. A 
sample of 1,000 was chosen for pragmatic reasons including time constraints for data generation. General consumers were chosen as target participants as the research team sought to generate a wide range of participants from different backgrounds to generate variance across the measurement items. The survey was administered online and the link to the survey was shared via social network platforms (LinkedIn, Facebook etc.) and as such utilized a convenience sampling technique. An overall response rate of $24.1 \%$ (241 respondents) was achieved. This response rate is strongly competitive in comparison with typical consumer behavior (Ha \& Stoel, 2009; Powers et al., 2009), marketing (Ilieva et al., 2002), strategy (e.g., Menon et al., 1999; Hodgkinson et al., 2016), and public sector management (Hodgkinson \& Hughes, 2014) research as well as favorably comparable with outcomes when using multiple survey response rate optimization techniques as discussed by Bednar and Westphal (2006) and Jin (2011). Of the 241 respondents, 191 respondents fully completed the questionnaire with 85 from the UK and 106 from the US. Reasons given for non-completion or partial completion included time constraints of the participants to complete the survey, indications from sampled participants that they did not gamble nor had a specific view on it, and many participants without offline/online gambling experience chose not to respond. Partially complete responses were in all instances a result of only responding to either offline or online gambling questions as per the individual's own preferred mode of gambling by those respondents.

Of the 241 respondents, $56.32 \%$ of the respondents were female, and $43.68 \%$ were male. The respondents varied in age from 18 to $75+$ years old; however, $96.3 \%$ were aged between 18 and 64 with a large proportion (50.26\%) of the respondents were aged between 25 and 34. There was a diverse range of occupations in a variety of roles that included students, administration, management, social services, the arts, academia, and home-makers. $71.5 \%$ of the respondents had gambled within the past 12 months, with only $22.2 \%$ having 
gambled online. $81 \%$ of the respondents indicated that their preferred method of gambling is offline. In the past twelve months, $70 \%$ of the respondents engaged in some gambling activity, with $94.6 \%$ (160) of this group having gambled offline and 36\% (61) having gambled online. Additionally, participants were asked to indicate their preferred method for gambling, with $70.5 \%$ (170) stating a preference for offline formats and $19.9 \%$ (48) stating a preference for online formats.

Participants were provided with the details of the study, as well as the collection and storage of all data before the initial questioning. All participants were guaranteed anonymity, confidentiality, and security. All participants provided informed consent to use the data collected. This study utilized data from a sample of general consumers. Participants did not need to have prior experience with gambling but needed to have an opinion regarding whether they would personally utilize online and offline gambling services. The inclusion of offline gambling here allows for a comparison with online gambling intention, which we use as the focus for additional analysis. Participants were asked to indicate the strength of their agreement or disagreement on a seven-point Likert scale rating technique to indicate the varying strength of individual perceptions for topics that surrounded the act of gambling online (Hair et al, 2006; Kline, 1994).

To limit common-method bias, the questionnaire was designed to: not imply expected answers, adopted neutral wording, not use leading questions, keep the questionnaire length short, and included random questions (e.g., on the existence of Father Christmas and the 'chicken and the egg' paradox) on topics entirely unrelated for gambling or indeed research (Spector \& Brannick, 1995; Podsakoff et al., 2003; Conway \& Lance, 2010). This latter technique was adopted so as to pull respondents out of any possibility of simply checking the same response number consistently as an answer. Analysis of the data obtained implies that all answers have a reasonable degree of variance and provides confidence that common 
method bias does not exist. All measures were analyzed in a single factor analysis as per the Harman one factor test, and no single common factor was derived: nine factors were extracted, accounting for $70.68 \%$ of total variance and the single largest factor accounted for merely $17.11 \%$ of total variance. When a single factor was specified for extraction, this single factor only accounted for $25.47 \%$ of total variance. Next, common method bias was examined for by use of a marker variable and the partial correlation procedure as advocated by Lindell and Whitney (2001) and Podsakoff et al. (2003). Should common method bias be a problem then it would be expected that the original regression results and the bias-adjusted results would differ significantly (e.g., Hodgkinson et al., 2016; Hughes et al., 2018). One of the random questions inserted into the survey as an a priori protection against common method bias was used as the marker variable for this analysis. Specifically, an item asking respondents to rate their ability to be a 'good listener' was used. As per the guidance of Lindell and Whitney (2001), this was not theoretically related to any of the constructs under investigation nor correlated with any of the constructs in the study. The correlations of this variable were partialed out from the study constructs to determine whether the path loadings and relationships found in the original regression results differ in any way (Hughes et al., 2018). The results are presented in Appendix 1 and 2. In comparing these results with the original results found in Tables 2 and 3, it is observed that there are no significant changes to any of the results, no paths change direction, and the values remain broadly similar on the whole. The a priori protections taken against common method bias, and the subsequent post hoc tests, provide confidence that common method bias is not affecting the data or is an explanatory factor in the results of the hypothesis tests. Accordingly, all results discussed henceforth are based on the original data.

\subsection{Measures}


To optimize reliability, several techniques were employed to ensure the accuracy of the data collection phase. All measures for this study were designed to capture the full potential of human characterization by using a seven-point Likert scale and were collected following the questionnaire protocol defined by Ajzen (1991). To address the potential for common method bias, several of the measures were reverse coded within questionnaire.

Attitude: were constructed with the objective of understanding personal evaluations regarding the act of gambling in both the online and offline contexts. The evaluations asked participants to scale beliefs of favorable or unfavorable evaluations of prior experiences, personal guilt, levels of enjoyment, trust, ease of access, ethical beliefs, and personal risk aversion. The theory of reasoned action/planned behavior adopts a non-traditional method for collecting attitudinal perceptions. According to the model, attitude is measured by the personal evaluations of the act in question (Ajzen \& Fishbein, 1969; Fredrick \& Dossett, 1983; Fitzmaurice, 2005).

Subjective Norms (Close): to capture Subjective Norm (close) the participants were asked to state the level of agreement or disagreement with statements that would indicate whether their family, friends or employers discouraged gambling and readily influenced behavior by giving negative evaluations. The measures for subjective norms were designed to understand the participants' evaluation of the views that significant others held toward online and offline gambling as well as the individual's motivation to comply (Ajzen, 1991). In continuing the application of the theory of reasoned action/planned behavior, subjective normative beliefs are said to influence an individual's intention to perform a given act.

Subjective Norms (Social): captures the influence of peer, media, and word of mouth evaluations on perceptions of online gambling. The traditional model proposes the social impact of close familial relations will determine behavioral intention. The traditional view of 
subjective norm refers to the perceived social pressures by those close to the individual to perform or not perform the behavior in question (Ajzen, 1991). The presence of the different mediums to socially interact and develop relations was of interest to this study.

Perceived Behavioral Control: was analyzed by asking the respondents to rate their confidence in their ability to achieve the desired outcomes of the act (Ajzen, 1991). Perceived behavioral control measures were adapted to understand the participants' level of selfefficacy, and confidence for desired outcomes in both the online and offline context. This measure included identifying perceptions of confidence in skill level, statistics, luck, and the ability to self-limit purchase patterns.

Behavioral Intention: to gamble online and offline were assessed utilizing seven-point agreement or disagreement scale to determine if the consumer has clear intentions to gamble offline or online more or less in the next year. Additionally, respondents were asked to state their level of agreement or disagreement with statements that surrounded their intent to engage in gambling in both the online and offline contexts.

Actual Behavioral Action: This measure was assessed by the frequency of past involvement and indicated a preference for repeat gambling. This preference was captured by requesting an evaluation of whether the respondent gambles on a daily, weekly, monthly, quarterly, or yearly basis. This dependent variable was measured through a single-item measure.

\subsection{Data screening}

A principal component analysis, utilizing Varimax with Kaiser Normalization rotation method, was conducted on all variables to identify the primary loading components. Factor loadings of .50 or less were automatically suppressed for the purposes of data analysis, and 
thus any item below this value was not included in any final factor structure, as per recommended practice (Hair et al, 2006; Kline, 1994) to ensure the final constructs were sufficiently reliable and robust. All extracted factors exhibited Eigenvalues greater than 1. After testing the reliability of the measures, two clear components of subjective normative beliefs were classified separately for the analysis. This included subjective norms (close), which indicated a correlation between family members and colleagues, and subjective norms (social), which indicated a separate correlation for those that have an influence on perceptions but do not have a close relationship with the individual, such as peer and word of mouth evaluations. For most measures, there was a strong correlation between all factors defining the variables. Both the act of gambling in general and the act of online gambling, seven components were identified for each and had an average of four variables per factor.

To further verify reliability, measures were tested utilizing Cronbach's Alpha. Alpha scores for all constructs achieved a score of .70 or higher, except for offline gambling attitudes. Although the communalities reflected a strong correlation, the alpha score for offline gambling attitudes was .64. This is contrasted with the online gambling analysis for attitude, which was a collection of similar measures for comparison, which achieved an alpha score of .70. Although the Alpha for offline gambling attitudes is below the .70 score that many researchers argue to be the acceptable level for reliability, we believe the inclusion of this construct in the analysis for hypothesis testing is acceptable as: a) this research and analysis is conducted in a relatively untested research context; b) Nunnally (1967) advises that a level of .50 or higher is an acceptable level to be utilized; and c) Schmitt (1996) finds that constructs with Alpha values below .50 in terms of reliability do not go on to seriously attenuate validity coefficients in their study of Alpha. Details on all measurement items can be found in Table 1 . 


\section{Results}

Multiple linear regression analysis is first conducted to test the antecedent paths (attitudes, subjective norms, and perceived behavioral control) to behavioral intent. Next, the relationship between behavioral intent and behavioral action is examined. Results are presented in Tables 2 and 3. We report the findings in sequential order in line with the hypotheses.

...Insert Table 2 and Table 3 Here...

Hypothesis 1 asserted that attitudes would be positively related to online gambling intention in a) the UK and b) the US. H1a and H1b are supported. Hypothesis 2 posited that subjective norms (close) would be positively related to online gambling intention in a) the $\mathrm{UK}$ and $\mathrm{b}$ ) the US. $\mathrm{H} 2 \mathrm{a}$ and $\mathrm{H} 2 \mathrm{~b}$ are null. Hypothesis 3 proposed that subjective norms (social) will be positively related to online gambling intentions in a) the UK and b) the US. $\mathrm{H} 3 \mathrm{a}$ and $\mathrm{H} 3 \mathrm{~b}$ are supported. Hypothesis 4 asserted that perceived behavioral would be positively related to online gambling intentions in a) the UK and b) the US. H4a and H4b are null. Hypothesis 5 examined the outcome of behavioral intention and proposed that online gambling intentions will be positively related to gambling online behavior in a) the UK and b) the US. The findings are reported in Table 3 and $\mathrm{H} 5 \mathrm{a}$ and $\mathrm{H} 5 \mathrm{~b}$ are supported.

\subsection{Online versus offline gambling intention}

Data were collected for both online and offline gambling perceptions in order to explore contrasts in the psychological antecedents of intention to gamble. The approach taken 
was due to previous evidence that suggests variations in the offline and online environments for consumer engagement (Gomez et al., 2018). Indeed, there were clear similarities and differences for gambling were uncovered between the US and UK contexts. For online gambling, in both country contexts attitude and wider social subjective norms influence gambling intentions; the other psychological antecedents tested are non-significant.

For offline gambling, attitude is again a driver of offline gambling intention along with perceived behavioral control. However, in the US context close subjective norms also negatively influence offline gambling intention; which is not the case in the UK country context. Ajzen's (1991) theory of reasoned action/planned behavior thus appears effective at determining offline gambling motives in the US, but not in the UK and not for online gambling platforms where peer evaluations and media appear to be very strong determinants.

\section{Discussion and conclusions}

For online gambling intentions both UK and US samples produced comparable results that indicate that the attitudinal and the subjective normative (social) perceptions are significant psychological influencers of the behavioral intention to gamble, while perceived behavioral control and subjective normative (close) are non-significant influencers. Thus, the attitudinal determinant was the only traditional measure defined by the theory of reasoned action/planned behavior to hold significance. In the context of online gambling, then, the theory of reasoned action/planned behavior may be outdated and not explain technological service engagement. This is not a surprise since Ajzen's (1991) theory was developed at a time where social networking, media, and consumer knowledge was less accessible than it is within contemporary current market capabilities. Nevertheless, the measures defined by the theory do hold for offline gambling in the US and this may be because of the service offering 
is more traditional in nature and the measures are more conceptually aligned to such a service offering. The finding reported for online gambling indicates a need to understand better the 'social' evaluations made by the digital consumer. Therefore, the theoretical implications for this study indicate a need for further development into the theory of reasoned action/planned behavior.

The digital service literature has emphasized the need for understanding of individualistic perceptions in the technology engagement process (Marangunic \& Granic, 2015), but this study finds that behavioral intent (and thus early engagement) is highly reliant upon broader social influences than previously suggested. This has implications for service managers as it indicates that an understanding of social context is essential in personal engagement with a gambling service. Specifically, the evidence suggests that the online format requires less approval or disapproval from immediate significant others (subjective norms [close]) due to the sense of anonymity that the online gambling service affords users. The novelty added by the study findings is that online gambling service users are instead influenced heavily by peer experiences from various forms of media within the wider social experience of individuals. The subjective normative beliefs, therefore, comprise a much more diverse set of norms and extent of influence than previously understood. The central implication for gambling operators and industry regulators is that the determinants of online gambling intention differ substantially from the determinants of traditional offline gambling.

Consequently, from the perspective of gambling operators', advertising and marketing efforts for greater consumer engagement need to focus on wider social messaging and experiential features of the service to increase consumer online gambling intention, which then should convert to action. For industry regulators they should not homogenize service users as gamblers but recognize that there are clear and significant differences in the psychological determinants of gambling between online and offline platforms. Appropriate 
regulatory controls should therefore target and address such differences. Finally, for policy makers, we extend the work of Ahn and Back (2018) from offline gambling contexts to further elucidate the drivers of behavioral online gambling intention and subsequent gambling behavior. Specifically, the findings may be used to better determine the difference between recreational and problem gamblers' future attitudes and behaviors, as highlighted in a call for future research made by Ahn and Back (2018). Observed differences in human behavioral intentions between traditional (offline) and technological (online) formats, as well as between nations, can inform policy makers to both allow gaming services to prosper while simultaneously taking informed measures to ensure that recreational online gamblers do not become problem online gamblers. Future research might focus on the collection of data from a broader more targeted population to characterize different social contexts and the depth of influence of different social systems from the perceptions of online gamblers.

This study has several academic and practical implications. The internet is increasingly prevalent in peoples' lives (Israeli et al., 2018) and none more so in digital consumer services such as online gambling. We examined digital services using the TAM due to its popularity within the digital service research realm and examine individual propensity to engage with online gambling technology. To do so, we reduced the TAM model back to its implicit theoretical roots of theory of reasoned actioned and theory of planned behavior and extended the core constructs to include contemporary wider social influences. We subsequently provide a cross-cultural (US and UK) and cross-context (offline traditional versus online digital gambling platforms) examination of psychological determinants of the intent to gamble and the relationship between this intent and the actual action of service consumption.

The study reports many similarities and differences between the US and UK contexts in the psychological determinants of gambling intention. For online gambling, the findings 
extend knowledge on the role of traditional 'subjective norms' by establishing a significant antecedent role of wider subjective norms that would be considered to be more societal or peer-related, rather than derived from close family ties, as initially inferred (Ajzen \& Fishbein, 1969). This social determinant was supplemented by the positive influence of attitude on the behavioral intention to gamble online, for both the UK and US samples. Differences were observed, however, when offline gambling was considered by study participants. US respondents adhered to the espoused determinants of the TAM (i.e., attitude, subjective norms [close] and perceived behavioral control), while subjective norms [close] had no observable impact on UK respondents offline gambling intention.

These variations are interesting for serval reasons. First, it supports previous work that suggests that the local environment impacts perceptions and engagement with products ( $\mathrm{Li}$ et al., 2018). Additionally, it demonstrates how variations between online and offline environments impacts consumer adoption and, thus, market diffusion within this context. As suggested by Gomex et al. (2017), these variations are likely to impact the ways in which firms develop a relationship with their consumers. Finally, the results further support the need for more studies to focus on the soft factors that influence their innovation capabilities (e.g. Hoflinger et al., 2018; Ali et al., 2018). The findings carry several implications: 1) for gambling operators', advertising and marketing efforts for greater online consumer engagement need to focus on wider social messaging; 2) for industry regulators, service users should not be homogenized as gamblers given the clear and significant differences in psychological determinants between online and offline platforms; 3) for policy makers, the findings may be used to better address problem gamblers. 


\section{References}

Ahn, J. Back, K-J., 2018. The structural effects of affective and cognitive elaboration in formation of customer-brand relationship, The Service Industries Journal, DOI: $10.1080 / 02642069.2018 .1460358$

Al-Debei, M.M., Al-Lozi, E., Papazafeiropoulou, A., 2013. Why people keep coming back to Facebook: explaining and predicting continuance participation from an extended theory of planned behavior perspective. Decision Support Systems, 55 (1), $43-54$.

Ali, M., Ali, I., Al-Maimani, K.A., Park, K., 2018. The effect of organizational structure on absorptive capacity in single and dual learning modes. Journal of Innovation and Knowledge, 3 (3), 108-114.

Ajzen, I., 1991. Theory of planned behavior. Organizational Behavior and Human Decision Processes, 50 (2), 179-211.

Ajzen, I., Fishbein, M., 1969. The prediction of behavioral intentions in a choice situation. Journal of Experimental Social Psychology, 5 (4), 400-416.

Baker, R.K., White, K.M., 2010. Predicting adolescents' use of social networking sites from an extended theory of planned behavior perspective. Computers in Human Behavior, 26 (6), 1591-1597.

Bakos, J., 1997. Reducing buyer search costs: implications for electronic marketplaces. Management Science, 43 (12), 1676-1692.

Bednar, M.K., Westphal, J.D., 2006. Surveying the corporate elite: theoretical and practical guidance on improving response rates and response quality in top management survey questionnaires. In D.J. Ketchen, D.D. Bergh (Eds.), Research Methodology in Strategy and Management. Emerald, Bingley, pp. 37-55.

Bratina, D., 2018. Elasticities and dynamics of online price promotions and advertising. Economic Research, 31 (1), 1228-1239. 
Conway, J.M., Lance, C.E., 2010. What reviewers should expect from authors regarding common method bias in organizational research. Journal of Business and Psychology, 25 (3), 325-334.

Cotte, J., Latour, K., 2009. Blackjack in the kitchen: understanding online versus casino gambling. Journal of Consumer Research, 35 (5), 742-758.

Davis, F.D., 1989. Perceived usefulness, perceived ease of use, and user acceptance of information technology. MIS Quarterly, 13 (3), 319-339.

Davis, F.D., Bagozzi, R.P., Warshaw, P.R., 1989. User acceptance of computer technology: a comparison of two theoretical models. Management Science, 35 (8), 982-1003.

Dillman, D.A., 2000. Mail and Internet Surveys: The Tailored Design Methods. John Wiley and Sons, New York.

Eggers, F., Hatak, I., Kraus, S., Niemand, T., 2017. Technologies that support marketing and market development in SMEs_Evidence from social networks. Journal of Small Business Management, 55 (2), 270-302.

Ferraris, A., Santoro, G., Bresciani, S., 2017. Open innovation in multinational companies' subsidiaries: the role of internal and external knowledge. European Journal of International Management, 11 (4), 452-468.

Ferreira, J.J., Fernandes, C.I., Kraus, S., 2019. Entrepreneurship research: mapping intellectual structures and research trends. Review of Managerial Science, 13 (1), 181-205.

Fitzmaurice, J., 2005. Incorporating consumers' motivations into the theory of reasoned action. Psychology and Marketing, 22 (11), 911-929.

Fredricks, A., Dossett, D., 1983. Attitude - behavior relations: a comparison of the Fishbein Ajzen and the Bentler - Speckart model. Journal of Personality and Social Psychology, $45(3), 501-512$. 
Gainsbury, S., Parke, J., Suhoen, N., 2013. Consumer attitudes toward internet gambling: Perceptions of responsible gambling policies, consumer protection, and regulation of online gambling sites. Computers in Human Behavior, 29 (1), 235-245.

Gambling Commission, 2013. Licensing and Compliance. Gambling Commission, Retrieved 6 September 2013 from http://www.gamblingcommission.gov.uk/licensing_complianceenfo.aspx

Gomez, M., Gonzalez-Diaz, B., Martin-Cosuegra, D., Molina, A., 2017. How do offline and online environments matter in the relational marketing approach? Economic ResearchEkonomska Istrazivanja, 30 (1), 368-380.

Ha, S., Stoel, L., 2009. Consumer e-shopping acceptance: Antecedents in a technology acceptance model. Journal of Business Research, 62 (5), 565-571.

Hair, J.F., Black, B., Babin, B., Anderson, R.E., Tatham, R.L., 2006. Multivariate Data Analysis (6th ed.). Prentice Hal, Upper Saddle River, N.J.

Hall, S., 1980. Cultural studies: two paradigms. Media, Culture, and Society, 2 (1): 57-72.

Heirman, W., Walrave, M., 2012. Predicting adolescent perpetration in cyberbullying: An application of the theory of planned behavior, Psicothema, 24 (4), 614-620.

Hodgkinson, I.R., Hughes, P., 2014. Strategy content and public service provider performance in the UK: an alternative approach. Public Administration, 92 (3), 707-726.

Hodgkinson, I.R., Hughes, P., Arshad, D.A., 2016. Strategy development: driving improvisation in Malaysia. Journal of World Business, 51 (3), 379-390.

Höflinger, P.J., Nagel, C., Sandner, P., 2018. Reputation for technological innovation: does it actually cohere with innovative activity? Journal of Innovation \& Knowledge, 3 (1), 2639.

Hughes, P., Hodgkinson, I.R., Hughes, M., Arshad, D., 2018. Explaining the entrepreneurial orientation-performance relationship in emerging economies: the intermediate roles of 
absorptive capacity and improvisation. Asia Pacific Journal of Management, 35 (4), 1025-1053.

Ilieva, J., Baron, S., Healey, N.M., 2002. Online surveys in marketing research: pros and cons. International Journal of Market Research, 44 (3), 361-382.

Israeli, A.A., Lee, S.A., Karpinski, A.C., 2018. The relationship between Internet addiction and negative eWOM. The Service Industries Journal, in press.

DOI:10.1080/02642069.2018.1453501

Jones, J.P., 2005. Entertaining Politics: New Political Television and Civic Culture. Rowman \& Littlefield, New York

Jin, L., 2011. Improving response rates in web surveys with default setting: the effects of default on web survey participation and permission. International Journal of Market Research, 53 (1), 75-94.

Kaplan, A., Haenlein, M., 2010. User of the world, unite! the challenges and opportunities of social media. Business Horizons, 53 (1), 59-68.

Kamolsook, A., Badir, Y., Frank, B., 2019. Consumers' switching to disruptive technology products: the role of comparative economic value and technology type, Technological Forecasting and Social Change, 140 (March), 328-340.

Kairouz, S., Paradis, C., Nadeau, L., 2012. Are online gamblers more at risk than offline gamblers? Cyberpsychology, Behavior, and Social Networking, 15 (3), 175-180.

King, W.R., He, J., 2006. A meta-analysis of the technology acceptance model. Information and Management, 43 (6), 740-755.

Kline, P., 1994. An Easy Guide to Factor Analysis. Routledge, London.

Kraus, S., Palmer, C., Kailer, N., Kallinger, F.L., Spitzer, J., 2019. Digital entrepreneurship: a research agenda on new business models for the twenty-first century. International Journal of Entrepreneurial Behavior \& Research, 25 (2), 353-375. 
Lamoreaux, N.R., Sokoloff, K.L., 2003. Intermediaries in the US market for technology, 1870 -1920. In S.L. Engerman, P.T. Hoffman, J-L. Rosenthal, K.L. Sokoloff (Eds.), Finance, Intermediaries, and Economic Development. Cambridge University Press, New York, pp. 209-246.

Lee, G., Pearce, G., 2007. Profiling online gamblers: an exploratory study. International Journal of Business Research, 7 (4), 109-118.

Lee, S.M., Trimi., S., 2018. Innovation for creating a smart future. Journal of Innovation and Knowledge, 3 (1), 1-8.

Lindell, M.K., Whitney., D.J., 2001. Accounting for common method variance in crosssectional designs. Journal of Applied Psychology, 86 (1), 114-121.

Menon, A., Bharadwaj, S.G., Adidam, P.T., Edison, S.W., 1999. Antecedents and consequences of marketing strategy making: a model and a test. Journal of Marketing, $63(2), 18-40$.

Nadeem, W., Andreini, D., Salo, J., Laukkanen, T., 2015. Engaging consumers online through websites and social media: a gender study of Italian generation y clothing consumers. International Journal of Information Management, 35 (4), 432-445.

Nelson, S.E., LaPlante, D.A., Peller, A.J., Schumann, A., LaBrie, R.A., Shaffer, H.J., 2008. Real limits in the virtual world: self-limiting behavior of Internet gamblers. Journal of Gambling Studies, 24 (4), 463-477.

Nunnally, J.C., 1967. Psychometric Theory. McGraw-Hill, New York.

Oner, M.A., Karaca, F., Beser, S.G., Yildirmaz, H., 2013. Comparison of nanotechnology acceptance in Turkey and Switzerland. International Journal of Technology Management, 10 (2), 1-21. 
Pai, F., Huang, K., 2011. Applying the technology acceptance model to the introduction of healthcare information systems, Technological Forecasting and Social Change, 78 (May), 650-660.

Parent, M., Plangger, K., Bal, A., 2011. The new wtp: willingness to participate. Business Horizons, 54 (3), 219-229.

Park, J., Song, Y., Teng, C., 2011. Exploring the links between personality traits and motivations to play online games. Cyberpsychology, Behavior, and Social Networking, $14(12), 747-751$.

Podsakoff, P., MacKenzie, S., Lee, J., Podsakoff, N., 2003. Common method biases in behavioral research: A critical review of the literature and recommended remedies. Journal of Applied Psychology, 87 (5), 879-903.

Powers, T.L., Bendall Valentine, D., 2009. Response quality in consumer satisfaction research. Journal of Consumer Marketing, 26 (4), 232-240.

Rajapathirana, R., Hui, Y., 2018. Relationship between innovation capability, innovation type, and firm performance. Journal of Innovation and Knowledge, 3 (1), 44-55.

Rigby, D., Sutherland, J., Takeuchi, H., 2016. Embracing agile. Harvard Business Review, 94 (5), 40-50.

Schmidthuber, L., Maresch, D., Ginner, M., 2019. Disruptive technologies and abundance in the service sector - toward a refined technology acceptance model. Technological Forecasting and Social Change. (Forthcoming)

Schmitt, N., 1996. Uses and abuses of coefficient alpha. Psychological Assessment, 8 (4), $350-353$.

Sepasgozar, S., Hawken, S., Sargolzaei, S., Foroozanfa, M., (2019). Implementing citizen centric technology in developing smart cities: a model for predicting the acceptance of urban technologies. Technological Forecasting and Social Change, 142 (May), 105-116. 
Siemens, J., Kopp, S., 2011. The influence of gambling environments on self-control. Journal of Public Policy and Marketing, 30 (2), 279-293.

Safón, V., 2010. Promotion of service industries by means of entry restriction: the case of operators in the slot machine industry. The Service Industries Journal, 30 (1), 85-97.

Spector, P.E., Brannick, M.T., 1995. The nature and effects of method variance in organizational research. In C.L. Cooper and I.T. Robertson (Eds), International Review of Industrial and Organizational Psychology, 10. Wiley, Chichester, pp. 249-274.

Storey, J., 2018. Culture Theory and Popular Culture: An Introduction. Routledge, London. Truong, Y., 2009. An evaluation of the theory of planned behavior in consumer acceptance of online video and television services. The Electronic Journal Information Systems Evaluation, 12 (2), 177-186.

Venkatraman, S., Cheung, C., Lee, Z., Davis, F. Venkatesh, V., 2018. The “darth" side of technology use: an inductively derived typology of cyberdeviance. Journal of Management Information Systems, 35 (4), 1060-1091

Verma, P., Sinha, N., 2018. Integrating perceived economic wellbeing to technology acceptance model: the case of mobile based agricultural extension service. Technological Forecasting and Social Change, 126 (January), 207-216.

Wang, Q., Sun, X., 2016. Investigating gameplay intention of the elderly using an extended technology acceptance model. Technological Forecasting and Social Change, 107 (June), 59-68.

Workman, M., 2007. Advancements in technology: new opportunities to investigate factors contributing to differential technology and information use. International Journal of Management and Decision Making, 8 (2), 318-342. 
Table 1. Factor analysis

\begin{tabular}{lllllll}
\hline Online Gambling & $\begin{array}{l}\text { Factor } \\
\text { Loading }\end{array}$ & $\begin{array}{l}\text { Items } \\
\text { included }\end{array}$ & N & Mean & Std. Dev A & A \\
\hline Intention & & 6 & 204 & 2.095 & 1.403 & .929
\end{tabular}

Please rate how likely it is that you will use

.841

an online gambling site in the next 12

months.

If your favourite wagering game is not

available online, how likely would you be to

utilize this service if it was made available

in an online format?

I intend to gamble online more frequently in the next year.

I intend to gamble online with more money

in the next year.

I intend to try more online gambling games

in the next year.

I intend to try different online gambling games in the next year.

\begin{tabular}{llllll} 
games in the next year. & & & \\
\hline Attitudes & 4 & 194 & 3.201 & 1.276 & .702
\end{tabular}

I like the convenience of gambling online.

.849

I am confident that most online transactions $\quad .825$

are secure.

I do not feel guilty when I gamble online.

Online gambling is my favourite form of

.565

entertainment.

\begin{tabular}{llllll}
\hline Subjective norms (close) & 3 & 192 & 4.642 & 1.427 & .843 \\
\hline
\end{tabular}

I would rather that my family did not know

.893

that I enjoy gambling online.

I would rather that my colleagues/boss did $\quad .910$

not know that I enjoy gambling online.

My family is critical of online gamblers. $\quad .768$

\begin{tabular}{llllll}
\hline Subjective norms (social) & 4 & 193 & 3.913 & 1.392 & .800
\end{tabular}

I know others that have had bad experiences $\quad .818$

with gambling online.

I have read or seen negative media coverage $\quad .751$

regarding online gambling.

I know others that have been had bad

experiences with online gambling.

I have heard a lot of bad things about

gambling online.

Perceived behavioral control

4

184

3.090

1.125

.723

Gambling online gives me greater control

over how much I spend.

I have little experience with gambling

online, but I would like to if I learned more

about it.

I feel like UI can apply more focus and skill

when I play online gambling games. 
Online gambling games are easier to play.

.722

\begin{tabular}{llllllll}
\hline Offline Gambling & Factor & Items & N & Mean & Std. Dev & A \\
& Loading & included
\end{tabular}

\begin{tabular}{|c|c|c|c|c|c|c|}
\hline Intention & & 4 & 232 & 2.234 & 1.364 & .898 \\
\hline $\begin{array}{l}\text { I intend to gamble more frequently in the } \\
\text { next year. }\end{array}$ & .828 & & & & & \\
\hline $\begin{array}{l}\text { I intend to gamble more money in the next } \\
\text { year. }\end{array}$ & .792 & & & & & \\
\hline $\begin{array}{l}\text { I intend to try more gambling games in the } \\
\text { next year. }\end{array}$ & .892 & & & & & \\
\hline $\begin{array}{l}\text { I intend to try different gambling games in } \\
\text { the next year. }\end{array}$ & .842 & & & & & \\
\hline Attitudes & & 3 & 219 & 4.580 & 1.235 & .640 \\
\hline
\end{tabular}

My prior experiences with gambling have $\quad .768$

been positive.

I do not feel guilty when I gamble, $\quad .816$

I feel gambling is unethical.

.639

\begin{tabular}{|c|c|c|c|c|c|c|}
\hline Subjective norms (close) & & 3 & 217 & 4.877 & 1.425 & .814 \\
\hline $\begin{array}{l}\text { I would rather that my family did not know } \\
\text { that I enjoy gambling. }\end{array}$ & .911 & & & & & \\
\hline $\begin{array}{l}\text { I would rather that my colleagues/boss did } \\
\text { not know that I enjoy gambling. }\end{array}$ & .912 & & & & & \\
\hline My family is critical of gamblers. & .717 & & & & & \\
\hline Subjective norms (social) & & 3 & 218 & 3.011 & 1.264 & .709 \\
\hline $\begin{array}{l}\text { I know others that have had bad experiences } \\
\text { with gambling. }\end{array}$ & .648 & & & & & \\
\hline $\begin{array}{l}\text { I have read or seen negative media coverage } \\
\text { regarding gambling. }\end{array}$ & .870 & & & & & \\
\hline $\begin{array}{l}\text { I have heard a lot of bad things about } \\
\text { gambling. }\end{array}$ & .844 & & & & & \\
\hline Perceived behavioral control & & 3 & 216 & 3.661 & 1.451 & .721 \\
\hline I would rate my gambling skill as advanced & .770 & & & & & \\
\hline $\begin{array}{l}\text { I am confident in my ability to play my } \\
\text { favourite games. }\end{array}$ & .848 & & & & & \\
\hline $\begin{array}{l}\text { I understand the statistical odds of winning } \\
\text { the games I play. }\end{array}$ & .732 & & & & & \\
\hline
\end{tabular}


Table 2. Psychological antecedents and behavioral intention

\begin{tabular}{|c|c|c|c|c|c|c|c|c|c|c|}
\hline \multirow[t]{3}{*}{ Online } & \multicolumn{5}{|c|}{ UK Data $(n=85)$} & \multicolumn{5}{|c|}{ US Data $(n=116)$} \\
\hline & \multicolumn{2}{|c|}{$\begin{array}{l}\text { Unstandardized } \\
\text { coefficients }\end{array}$} & \multirow{2}{*}{$\begin{array}{c}\text { Standard } \\
\text { CE } \\
\text { Beta }\end{array}$} & \multirow[b]{2}{*}{$\begin{array}{c}t \\
\text { value }\end{array}$} & \multirow[b]{2}{*}{ p value } & \multicolumn{2}{|c|}{$\begin{array}{c}\text { Unstandardized } \\
\text { Coefficients }\end{array}$} & \multirow{2}{*}{$\begin{array}{c}\text { Standard } \\
\text { CE } \\
\text { Beta }\end{array}$} & \multirow[b]{2}{*}{$\begin{array}{c}t \\
\text { value }\end{array}$} & \multirow[b]{2}{*}{ p value } \\
\hline & $\boldsymbol{\beta}$ & SE & & & & B & SE & & & \\
\hline Constant & -.033 & .568 & & -.058 & .954 & .851 & .696 & & 1.221 & .225 \\
\hline Attitude & .755 & .106 & .663 & 7.130 & $.000 * *$ & .548 & .106 & .502 & 5.187 & $.000 * *$ \\
\hline $\begin{array}{l}\text { Subjective } \\
\text { Norms (close) }\end{array}$ & -.024 & .085 & -.025 & -.279 & .781 & .033 & .093 & .033 & .354 & .724 \\
\hline $\begin{array}{l}\text { Subjective } \\
\text { Norms } \\
\text { (social) }\end{array}$ & -.246 & .104 & -.205 & -2.366 & $.021 *$ & -.208 & .076 & -.239 & -2.741 & $.007 * *$ \\
\hline $\begin{array}{l}\text { Perceived } \\
\text { Behavioral } \\
\text { Control }\end{array}$ & .178 & .111 & .142 & 1.602 & .113 & .026 & .118 & .023 & .223 & .824 \\
\hline $\mathbf{R}^{2}$ & & & & & $=.528$ & $\mathbf{R}^{2}$ & & & & $=.345$ \\
\hline F value & & & & & $=20.995 * *$ & F Value & & & & $12.258 * *$ \\
\hline Offline & & & & & & & & & & \\
\hline Constant & .230 & .563 & & .409 & .683 & 1.154 & .699 & & 1.651 & .102 \\
\hline Attitude & .191 & .115 & .171 & 1.654 & $.100 \dagger$ & .329 & .104 & .294 & 3.176 & $.002 * *$ \\
\hline $\begin{array}{l}\text { Subjective } \\
\text { Norms (close) }\end{array}$ & -.144 & .088 & -.150 & -1.628 & .107 & -.188 & .103 & -.166 & -1.815 & $.072 \dagger$ \\
\hline $\begin{array}{l}\text { Subjective } \\
\text { Norms } \\
\text { (social) }\end{array}$ & . 010 & .111 & .008 & .094 & .925 & -.074 & .089 & -.075 & -.827 & .410 \\
\hline $\begin{array}{l}\text { Perceived } \\
\text { Behavioral } \\
\text { Control }\end{array}$ & .463 & .092 & .491 & 5.015 & $.000 * *$ & .229 & .086 & .243 & 2.656 & $.009 * *$ \\
\hline $\mathbf{R}^{2}$ & & & & & $=.327$ & $\mathbf{R}^{2}$ & & & & $=.206$ \\
\hline F value & & & & & $=11.159 * *$ & F value & & & & $=6.830 * *$ \\
\hline
\end{tabular}


Table 3. Behavioral intention and behavioral action

\begin{tabular}{lll}
\hline Online & UK Data $(n=85)$ & US Data $(n=116)$
\end{tabular}

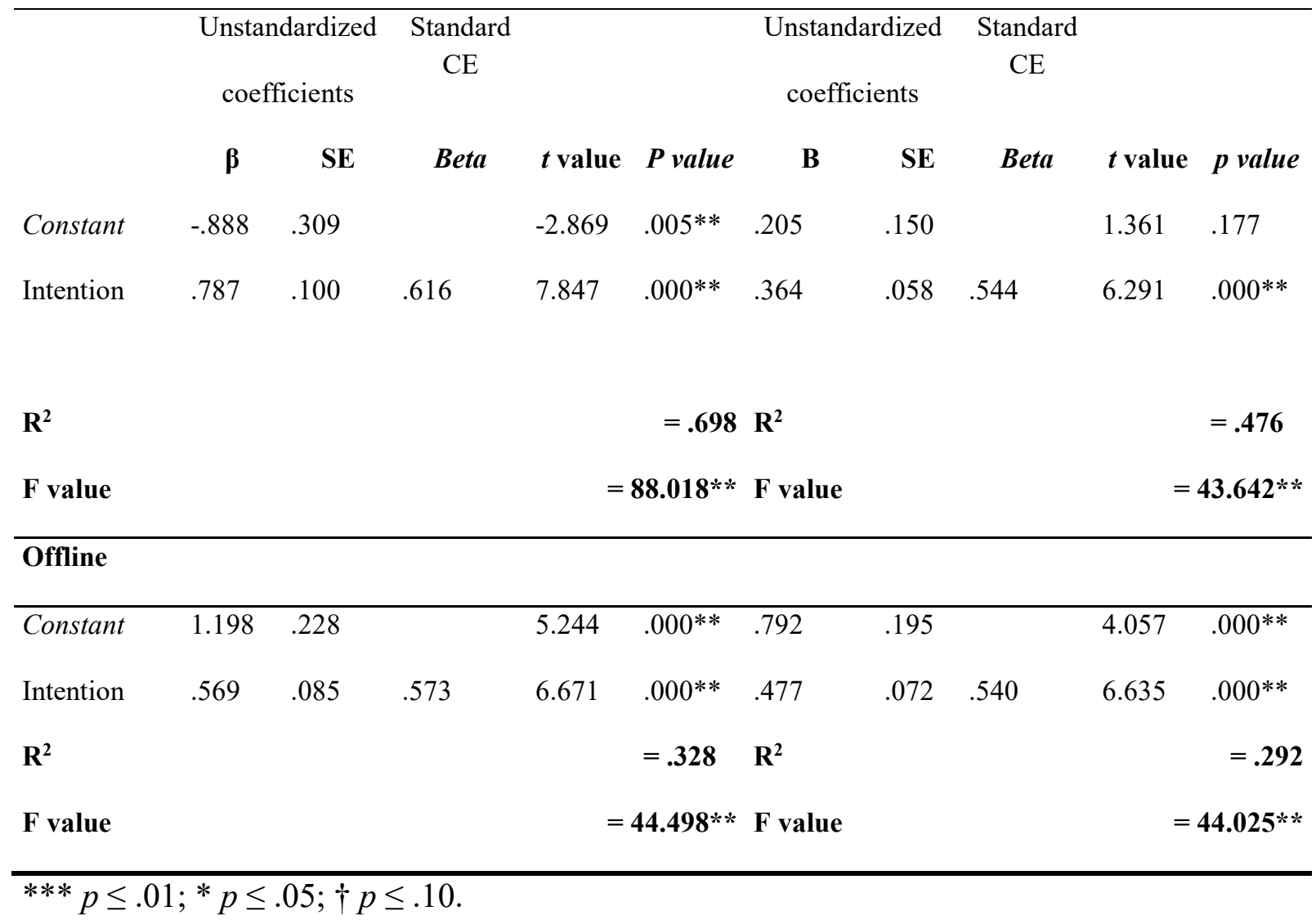


Appendix 1. Common method bias: behavioral intention regression results after marker variable partial correlation procedure

\begin{tabular}{|c|c|c|c|c|c|c|c|c|c|c|}
\hline \multirow[t]{3}{*}{ Online } & \multicolumn{5}{|c|}{ UK Data $(n=85)$} & \multicolumn{5}{|c|}{ US Data $(n=116)$} \\
\hline & \multicolumn{2}{|c|}{$\begin{array}{c}\text { Unstandardized } \\
\text { coefficients }\end{array}$} & \multicolumn{2}{|c|}{$\begin{array}{l}\text { Standard } \\
\text { CE }\end{array}$} & & \multicolumn{2}{|c|}{$\begin{array}{l}\text { Unstandardized } \\
\text { Coefficients }\end{array}$} & \multicolumn{2}{|c|}{$\begin{array}{l}\text { Standard } \\
\mathrm{CE}\end{array}$} & \multirow[b]{2}{*}{ p value } \\
\hline & $\beta$ & SE & Beta & $\begin{array}{c}t \\
\text { value }\end{array}$ & p value & B & SE & Beta & $\begin{array}{c}t \\
\text { value }\end{array}$ & \\
\hline Constant & -.224 & .140 & & -1.606 & .112 & -.013 & .111 & & -.118 & .906 \\
\hline Attitude & .757 & .110 & .659 & 6.884 & $.000 * *$ & .555 & .102 & .517 & 5.419 & $.000 * *$ \\
\hline $\begin{array}{l}\text { Subjective } \\
\text { Norms (close) }\end{array}$ & -.021 & .088 & -.022 & -2.41 & .811 & .042 & .091 & .042 & .457 & .649 \\
\hline $\begin{array}{l}\text { Subjective } \\
\text { Norms } \\
\text { (social) }\end{array}$ & -.262 & .107 & -.217 & -2.452 & $.017^{*}$ & -.194 & .075 & -.223 & -2.587 & $.011^{*}$ \\
\hline $\begin{array}{l}\text { Perceived } \\
\text { Behavioral } \\
\text { Control }\end{array}$ & .170 & .116 & .133 & 1.461 & .148 & .039 & .116 & .034 & .336 & .738 \\
\hline $\mathbf{R}^{2}$ & & & & & $=.515$ & $\mathbf{R}^{2}$ & & & & $=.362$ \\
\hline F value & & & & & $=19.668 * *$ & F Value & & & & $13.208 * *$ \\
\hline Offline & & & & & & & & & & \\
\hline Constant & -.174 & .140 & & -1.243 & .218 & .187 & .129 & & 1.442 & .153 \\
\hline Attitude & .288 & .124 & .262 & 2.314 & $.023 *$ & .339 & .107 & .300 & 3.156 & $.002 * *$ \\
\hline $\begin{array}{l}\text { Subjective } \\
\text { Norms (close) }\end{array}$ & -.091 & .094 & -.100 & -.972 & .334 & -.195 & .106 & -.173 & -1.838 & $.069 \dagger$ \\
\hline $\begin{array}{l}\text { Subjective } \\
\text { Norms } \\
\text { (social) }\end{array}$ & -.042 & .113 & -.035 & -.367 & .715 & -.110 & .092 & -.111 & -1.195 & .235 \\
\hline $\begin{array}{l}\text { Perceived } \\
\text { Behavioral } \\
\text { Control }\end{array}$ & .360 & .096 & .419 & 3.751 & $.000 * *$ & .206 & .088 & .221 & 2.329 & $.022 *$ \\
\hline $\mathbf{R}^{2}$ & & & & & $=.325$ & $\mathbf{R}^{2}$ & & & & $=.210$ \\
\hline F value & & & & & $=9.015^{* *}$ & F value & & & & $=6.439 * *$ \\
\hline
\end{tabular}

$* * * p \leq .01 ; * p \leq .05 ; \dagger p \leq .10$. 
Appendix 2. Common method bias: behavioral action regression results after marker variable partial correlation procedure

\begin{tabular}{|c|c|c|c|c|c|c|c|c|c|c|}
\hline \multirow{3}{*}{ Online } & \multicolumn{5}{|c|}{ UK Data $(n=85)$} & \multicolumn{5}{|c|}{ US Data $(n=116)$} \\
\hline & \multicolumn{2}{|c|}{$\begin{array}{l}\text { Unstandardized } \\
\text { coefficients }\end{array}$} & \multirow{2}{*}{$\begin{array}{c}\text { Standard } \\
\text { CE } \\
\text { Beta }\end{array}$} & \multirow[b]{2}{*}{$t$ value } & \multirow[b]{2}{*}{ P value } & \multicolumn{2}{|c|}{$\begin{array}{c}\text { Unstandardized } \\
\text { coefficients }\end{array}$} & \multirow{2}{*}{$\begin{array}{c}\text { Standard } \\
\text { CE } \\
\text { Beta }\end{array}$} & \multirow[b]{2}{*}{$t$ value } & \multirow[b]{2}{*}{ p value } \\
\hline & $\boldsymbol{\beta}$ & SE & & & & B & $\mathbf{S E}$ & & & \\
\hline Constant & 2.099 & .127 & & 16.536 & $.000 * *$ & 1.388 & .063 & & 22.168 & $.000 * *$ \\
\hline Intention & .966 & .084 & .790 & 11.508 & $.000 * *$ & .437 & .051 & .653 & 8.629 & $.000 * *$ \\
\hline $\mathbf{R}^{2}$ & & & & & $=.623$ & $\mathbf{R}^{2}$ & & & & $=.421$ \\
\hline F value & & & & & $32.434 * *$ & F value & & & & $74.460 * *$ \\
\hline \multicolumn{11}{|l|}{ Offline } \\
\hline Constant & 2.444 & .134 & & 18.291 & $.000 * *$ & 1.798 & .096 & & 18.667 & $.000 * *$ \\
\hline Intention & .565 & .099 & .542 & 5.696 & $.000 * *$ & .454 & .071 & .533 & 6.390 & $.000 * *$ \\
\hline $\mathbf{R}^{2}$ & & & & & $=.294$ & $\mathbf{R}^{2}$ & & & & $=.284$ \\
\hline F value & & & & & $32.449 * *$ & F value & & & & $40.837 * *$ \\
\hline
\end{tabular}

*** $p \leq .01 ; * p \leq .05 ; \dagger p \leq .10$. 